\title{
BMJ Individual-level, network-level and Open city-level factors associated with HIV prevalence among people who inject drugs in eight Russian cities: a cross-sectional study
}

\author{
Ksenia Eritsyan, ${ }^{1,2}$ Robert Heimer, ${ }^{3}$ Russell Barbour, ${ }^{3}$ Veronika Odinokova, ${ }^{1}$ \\ Edward White, ${ }^{3}$ Maia M Rusakova, ${ }^{1}$ Tatiana T Smolskaya, ${ }^{4}$ Olga S Levina ${ }^{1}$
}

To cite: Eritsyan K, Heimer R, Barbour R, et al. Individuallevel, network-level and city-level factors associated with HIV prevalence among people who inject drugs in eight Russian

cities: a cross-sectional study. BMJ Open 2013;3: e002645. doi:10.1136/ bmjopen-2013-002645

- Prepublication history for this paper are available online. To view these files please visit the journal online (http://dx.doi.org/10.1136/ bmjopen-2013-002645).

Received 28 January 2013 Revised 3 April 2013 Accepted 5 April 2013

This final article is available for use under the terms of the Creative Commons Attribution Non-Commercial 2.0 Licence; see http://bmjopen.bmj.com

For numbered affiliations see end of article.

\footnotetext{
Correspondence to

Ksenia Eritsyan;

ksenia.eritsyan@gmail.com, ksenia@ngostellit.ru
}

\section{ABSTRACT}

Objectives: To ascertain HIV prevalence among people who inject drug (injection drug users (IDUs)) in the Russian Federation and identify explanations for the disparity in different cities.

Design: Cross-sectional survey with serological testing for HIV and hepatitis $\mathrm{C}$ virus prevalent infections.

Setting: 8 Russian cities-Irkutsk, Omsk, Chelyabinsk, Yekaterinburg, Naberezhnye Chelny, Voronezh, Orel and St Petersburg.

Participants: In 2007-2009 active IDUs were recruited by respondent-driven sampling with a target sample size of 300 or more in each city.

Main outcome measures: Participants were administered a questionnaire covering sociodemographics, injection risk and protective behaviours, sexual behaviours, HIV knowledge, experiences with drug treatment and harm reduction programmes and social networks. Participants were tested for HIV and hepatitis C by enzyme immunoassay. Data were analysed to identify individual-level, network-level and city-level characteristics significantly associated with HIV prevalence. Factors significant at $p \leq 0.1$ were entered into a hierarchical regression model to control for multicollinearity.

Results: A total of 2596 active IDUs were recruited, interviewed and tested for HIV and hepatitis $\mathrm{C}$ virus infection. HIV prevalence ranged from $3 \%$ (in Voronezh) to $64 \%$ (in Yekaterinburg). Although individual-level and network-level variables explain some of the difference in prevalence across the eight cities, the over-riding variable that seems to account for most of the variance is the emergence of commercial, as opposed to homemade, heroin as the predominant form of opioid injected.

Conclusions: The expansion of commercial heroin markets to many Russian cities may have served as a trigger for an expanding HIV epidemic among IDUs in that country.

\section{ARTICLE SUMMARY}

Article focus

- To test the hypotheses that differences in HIV prevalence among injection drug users (IDUs) could be explained by different level variables such as individual injection practices, the type of drug(s) injected, average duration of drug use, structure of IDU populations, interaction within social networks of IDUs or a combination of these factors.

Key messages

- The difference in HIV prevalence is best explained by city-level difference in the type of drug injected.

- HIV-prevention programmes targeting injectors that increase knowledge and reduce injection risk may reduce transmission, even in cities that have already experienced large epidemic.

Strengths and limitations of this study

- The largest side-by-side comparison of HIV and hepatitis $C$ virus prevalence among IDUs linked to individual level behavioural and higher order social network and city level data yet conducted in Russia.

- Change in the structure of the heroin market emerged as a possible explanation for the differences in HIV prevalence detected in the eight cities.

- Non-random selection of the eight cities, nonprobability respondent-driven sampling method.

- Cross-sectional design prevents determination of temporality needed to demonstrate causative link between changing heroin market and increasing HIV prevalence.

\section{INTRODUCTION}

The Russian Federation has experienced one of the fastest growing HIV/AIDS epidemics observed anywhere in the world since 
significant spread began in 1996. ${ }^{1}{ }^{2}$ The number of officially registered people with HIV increased over 250-fold between 1996 and 2011, from 2600 to more than 650000 officially diagnosed cases. ${ }^{3}$ Most recent estimates place the number of infections countrywide at around 1 million (840 000-1 200000), with an estimated HIV prevalence among Russian adults in 2009 around 1\% $(0.9-1.2 \%) .^{2}$

Since 1996, the HIV epidemic in Russia has been largely driven by injection drug use. ${ }^{4}$ There are almost 400000 officially registered injection drug users (IDUs) in Russia ${ }^{5}$; the estimated number is several times higher: 1.5-2.2 million. ${ }^{6-8}$ IDUs comprise nearly $80 \%$ of the registered HIV cases. ${ }^{4}$ Surveillance data indicate great regional differences in HIV prevalence among IDU population; the rates of HIV-prevalence among IDUs in governmental treatment and rehabilitation programmes range between $0 \%$ and $48 \% .^{5}$ These data are supported by research that found HIV prevalence among IDUs ranging from $3 \%$ to $56 \% .^{9-11}$ Factors that may give rise to the observed variation in HIV prevalence include individual-level parameters (eg, hygienic or unhygienic injection and sex practices), social network parameters (eg, factors that may influence the proportions of IDUs in network who are exposed) and city-level parameters (eg, time of entry of the virus into the local IDUs population, size of IDU population, type of drug and characteristics of drug markets).

By 2012, the official case notification surveillance data at the outset of the study from the oblasts (provinces) in which these eight cities are located revealed a wide range in HIV prevalence for the province as a wholefrom less than 40 cases/100 000 in Voronezh oblast (38.6) to more than 1000 cases/100 000 in Sverdlovsk oblast (Yekaterinburg, 1063.5) and Irkutsk oblast (1349.3), with intermediate rates in the other regions. ${ }^{3}$ In addition to HIV, hepatitis $\mathrm{C}$ virus (HCV) is endemic among IDUs. ${ }^{12-14}$ However, data on the prevalence of $\mathrm{HCV}$ in Russian IDUs are insufficient. In the few Russian locales where serological data on HIV and HCV are available, HCV prevalence exceeds that for HIV. ${ }^{11}{ }^{15}$ This is not only true in Russia but also in most of the world. ${ }^{16}$

Major differences among IDUs within Russia are the type and formulation of the drugs they inject. The two dominant drugs are heroin and methamphetamine-type stimulants (MTS). Both have a history of home manufacture-heroin from poppies or opium gum and MTS from ephedrine, pseudoephedrine or phenylpropanolamine-and are frequently prepared, stored and sold to IDUs as liquids. ${ }^{17-20}$ Homemade MTS involves reduction to methamphetamine or amphetamine, or oxidation to methcathinone or cathinone. Since our ethnographic studies of Russian IDUs who manufacture or use MTS suggested that they often confused oxidation and reduction and could not reliably report what MTS they either made or injected, ${ }^{18}{ }^{21}$ we group all these drugs into a single MTS category. Homemade heroin involves the extraction of the morphine in alkaline, organic extraction, acid back extraction and conversion of the morphine to heroin (diacetylmorphine). However, in many parts of Russia, homemade heroin has been replaced by commercial heroin trafficked directly from Central Asia. $^{7}{ }^{22}$ This transition took place in the late $1990 \mathrm{~s}$ jointly with a rapid increase of HIV epidemic in Russia. ${ }^{23}$

Our interest in the variation in HIV prevalence among IDUs was engaged by the opportunity to conduct behavioural and serological data collection and analysis in eight diverse Russian cities-Irkutsk, Omsk, Yekaterinburg, Chelyabinsk, Naberezhnye Chelny, Voronezh, Orel and St Petersburg using the same sampling approach-respondent-driven sampling (RDS) and virtually identical data collection instruments in all eight cities. The work has yielded the largest side-by-side comparison of HIV and HCV prevalence linked to individual-level behavioural and higher order social network and city level data yet conducted in Russia. Observations from prior studies ${ }^{19}{ }^{24-26}$ led us to formulate the hypotheses that differences in HIV prevalence will be explained by different level variables such as: individual injection practices, the type of $\operatorname{drug}(\mathrm{s})$ injected, average duration of drug use, percentage of men and women in particular IDU populations, interaction within social networks of IDUs or a combination of these factors. The resulting analysis permits an exploration of the associations of HIV infection with individual-level, network-level and city-level parameters. Owing to the factors that influence the likelihood of infection acting on different levels, it is necessary to develop a hierarchical approach in forging analytical strategies.

\section{METHODS}

\section{Recruitment procedure}

Recruitment using RDS of IDUs was conducted in eight Russian cities-Voronezh, Orel, Naberezhnye Chelny, Yekaterinburg, Chelyabinsk, Omsk and Irkutsk-with a target of 300 IDUs in each city and St Petersburg with target sample of 400 IDUs (figure 1). The sample size was set by the study funders and based on many international studies they were supporting at the same time. For inclusion in the study, participants had to be at least 15 years old and to report having injected drugs in the last month. In accordance with RDS methodology, the initial participants of the study, known as 'seeds', were members of the target IDU population in their respective cities, and were selected based on their willingness to recruit their peers into the study. ${ }^{27}{ }^{28}$ Sample sizes were set to achieve samples consistent with previous work that held such sample sizes reached sample equilibrium and reduced the biases introduced by non-random selection of seeds. ${ }^{29-31}$ Recruitment was initiated with $6-7$ seeds in each city referred from local organisations, governmental and/or non-governmental, conducting an outreach or the other kind of work with the IDU population. 


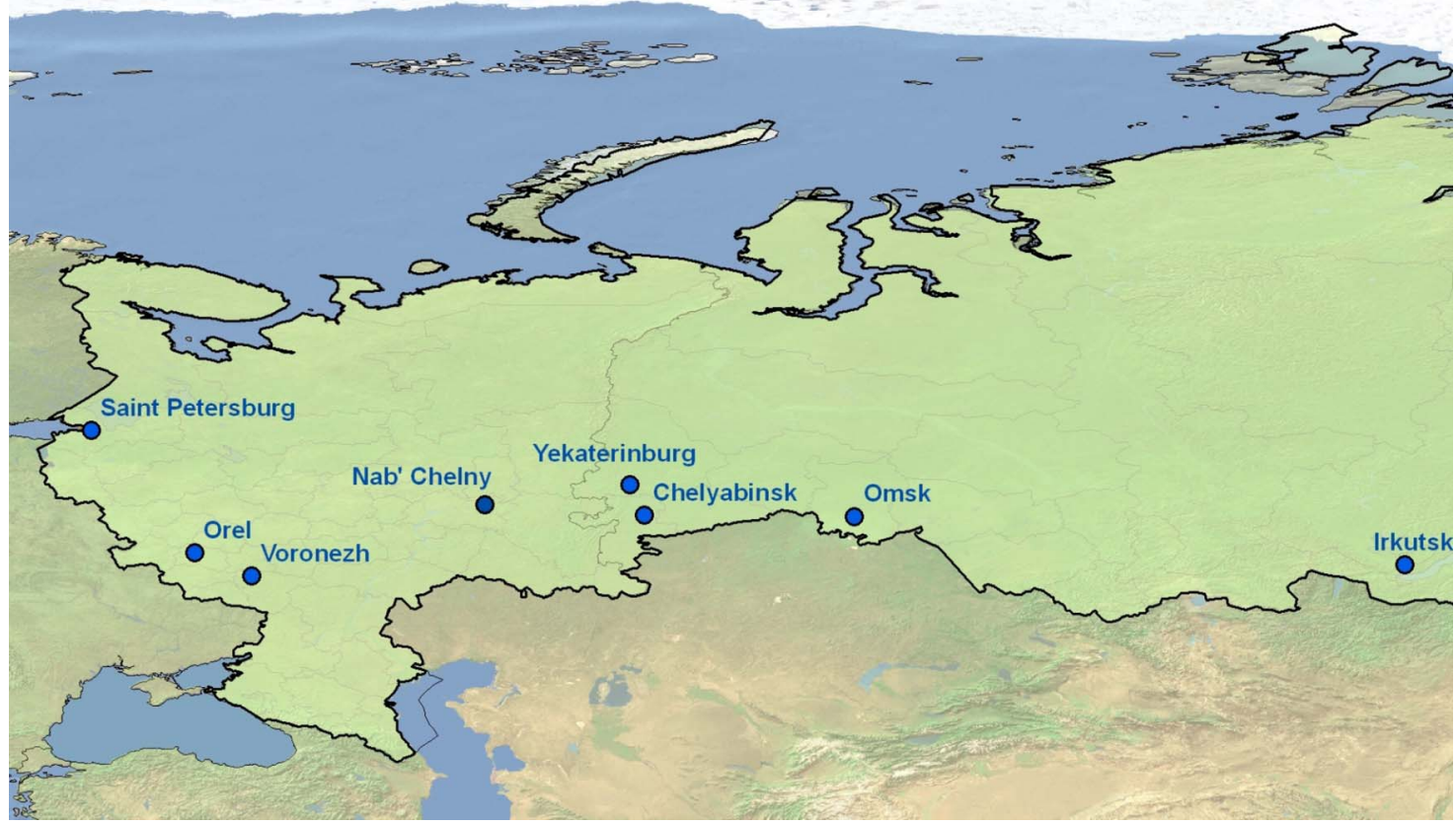

Figure 1 Recruitment using respondent-driven sampling of injection drug users was conducted in eight Russian citiesVoronezh, Orel, Naberezhnye Chelny, Yekaterinburg, Chelyabinsk, Omsk and Irkutsk.

Non-productive seeds were replaced such that in sum the sample was collected relying on 6-24 productive and 0-75 unproductive seeds in each city. A total of 2582 IDUs were recruited between November 2007 and October 2009.

Each person recruited and enrolled in the study received three recruitment coupons to recruit his/her peers in the study. Coupon distribution ceased when the sample size was reached after which participants were warned that the study would be ending within a few days. Coupons consisted of three parts that could be easily separated. All parts had the same unique number printed on them. One part of the coupon served as the 'referral coupon', which the recruiter used to recruit his peers into the study and the other part served as the 'payment coupon' and was kept by the recruiter to claim an incentive for having recruited his peers into the study. The third one has to be used by the respondent wanting to know the results of his/her blood testing. Each enrolling participant was given a unique consecutive ID number in addition to the coupon number.

Participants were given a gift package consisting of food (chocolate, a can of coffee or tinned goods) and personal hygiene products (shaving items and shampoo). The gifts were equivalent to US $\$ 14$ for participation and US $\$ 7$ for each recruit referred to and enrolled into the study. Recognition of potential duplicate participants depended upon study staff who were outreach workers familiar with the target population.

The final sample sizes of participants for whom both behavioural and serological data were collected in each city were 279 in Irkutsk, 350 in Omsk, 306 in
Chelyabinsk, 300 in Yekaterinburg, 341 in Naberezhnye Chelny, 309 in Voronezh, 300 in Orel and 411 in St Petersburg. Sample accrual time ranged between 5.5 and 22 weeks.

\section{Collection of demographic, behavioural and serological data}

The data collection was preceded by a written informed consent. To ensure the participants' anonymity, they were allowed to put a false signature on the consent paper. Data collection consisted of face-to-face interviews and blood specimens. The data collection team at each site consisted of one nurse, one or two interviewers and one person serving as coupon manager, all supervised by a study coordinator. The coupon manager recorded data for each participant on a form that included each individual ID, the coupon number brought to the interview and the coupon numbers each new participant was given for distribution. Interviewers were chosen based on their personal experience working with IDU populations (social workers, psychologists or epidemiologists from the local NGO or AIDS Center).

In Naberezhnye Chelny, Voronezh, Yekaterinburg and Omsk data collection occurred at a single site based in Regional AIDS Center and in Chelyabinsk and Orel data collection occurred at a single site operating from a van parked at one fixed location. In Irkutsk, there were multiple study sites: one site was based in Regional AIDS Center and two or three others were located outside the city centre and operated special hours at weekdays from mobile vans at fixed locations. In St Petersburg, five sites operated at regional narcology (drug treatment) clinics. 
After the interview and pretest counselling, blood specimens were collected by venipuncture $(3-5 \mathrm{ml}$ of blood) using closed vacuum systems into tubes marked with the participant's unique ID (a combination of coupon and consecutive participation number). HIV testing was performed using an enzyme-linked immunoassay with confirmatory western blot at the laboratories of Regional AIDS Center in each participating city. Participants were instructed to return in 7-14 days for their test results. During the post-test visit, the HIV-positive participants were counselled and referred for long-term care to physicians working at Regional AIDS Centers.

Questionnaire topics included network sizes information, sociodemographic indicators, sexual and drug injection risk behaviours during the 30 days prior to interview, knowledge of HIV and STIs and previous HIV testing. The questionnaire was based on FHI guidelines for conducting behavioural surveillance. ${ }^{32}$ Survey duration was approximately $1 \mathrm{~h}$.

\section{Data analysis}

Data from the eight cities were compiled into a single database. Descriptive statistics, bivariate associations between HIV prevalence and other variables and hierarchical models were produced using SPSS and R software. Initially, three models to identify the factors associated with HIV prevalence were generated. Because missing data represented $<4 \%$ (106 of 2596) of individuals, they were excluded from the models. In the first model, only individual-level variables with bivariate associations with $\mathrm{p} \leq 0.1$ were entered into a backward stepwise process using the 'step' command in $\mathrm{R}$, which is based on the best Akaike Information Criteria. In the resulting multivariate model, all remaining variables were considered significant if $p \leq 0.05$. A second model added to the first model three measures of network characteristics-participants' self-reported network size (number of IDUs participant met personally during the last 6 months), the mean number of participants in the RDS chain in the city and the frequency of meeting one's recruiter. This second model contains all those variables that remained significant at $p \leq 0.05$. A third model added into the second model three city level variables. The first two variables-the dominant form of heroin (homemade vs commercial) and high or low proportions of individuals injecting MTSs-are dichotomous; the third-the average length of RDS chains in each city-is a continuous variable. Again, the third model contains all those variables that remained significant at $\mathrm{p} \leq 0.05$.

The multicollinearity of the city-level variable of predominant commercial heroin and all other variables significant in the third model was tested using bivariate analysis. A binomial distribution within generalised linear models (GLM) for both univariate and multivariate analyses was implemented using $\boldsymbol{R}$ software (http:// r-forge.r-project.org). Hierarchical modelling applied the $<\mathbf{h g l m}>$ command within the $\mathbf{h g l m}$ package in $\boldsymbol{R}^{33}$ specifying commercial availability of heroin by city as a random variable, with demographic, network and individual injection risk behaviours that were found statistically significant in the aforementioned GLM specified as fixed variables.

\section{RESULTS}

A comparison of the demographic data from across the eight cities revealed strong similarities for seven of the eight cities (table 1). In these seven cities, the percentage of male IDUs ranged from $69 \%$ to $76 \%$ and the mean and median ages were in the range 26-31 and 26-30, respectively. The exception was Chelyabinsk, where $89 \%$ of IDUs were men and the mean and median ages were 24.7 and 24, respectively. In addition, the duration of injection among IDUs in Chelyabinsk was 6 years, less than in any city other than Orel. The majority of participants had completed secondary education through the Russian equivalent of the 10th grade, and $7-27 \%$ in each city had at least some postsecondary education.

HIV prevalence, the primary dependent variable, ranged from $3 \%$ in Voronezh to $64 \%$ in Yekaterinburg. HCV prevalence ranged from $49 \%$ in Naberezhnye Chelny to $90 \%$ in Yekaterinburg and St Petersburg.

In terms of individual-level injection risk behaviours, the majority of participants in each city reported never having been injected with a used syringe during the 30 days prior to interview (range 61-86\%). Many, however, during this same period reported sharing other injection paraphernalia (range 26-91\%) and engaging in other practices with the potential to transmit HIV or HCV (table 1). Engagement with services for IDUs was sporadic. Most had no recent contact with harm-reduction programmes (range 65-95\%) and only one-quarter were in a drug treatment programme in the preceding year (range $7-45 \%$ ).

The drug injected most frequently was one of several forms of heroin-either commercially trafficked or home manufactured (from opium, poppy straw or poppy seeds). The data in table 1 reveal that most IDUs in any given city inject with either the homemade or commercial variety, but not both. Prevalence of injection of commercial heroin was $95-100 \%$ in six of the eight cities-Irkutsk, Omsk, Chelyabinsk, Yekaterinburg, Naberezhnye Chelny and St Petersburg-but uncommon in the other two cities. Injection of MTS was less common, with prevalences ranging from $30 \%$ in Yekaterinburg to $2 \%$ in Voronezh and $0 \%$ in Irkutsk.

We developed stepwise models to identify factors associated with HIV prevalence across the eight cities. In the first model, which included only the individual-level variables from table 1 , we found that 7 of the 14 were associated in bivariate analysis (table 2), but when these seven were included in a multivariate model only four remained significant. Injecting with someone known to be HIV-positive and sharing rinse water were positively 
Table 1 Individual-level, network-level and city-level variables for IDUs in eight Russian cities

\begin{tabular}{|c|c|c|c|c|c|c|c|c|}
\hline & Irkutsk & Omsk & Chelyabinsk & Yekaterinburg & $\begin{array}{l}\text { Naberezhnye } \\
\text { Chelny }\end{array}$ & Voronezh & Orel & St Petersburg \\
\hline Sample size & 279 & 350 & 306 & 300 & 341 & 309 & 300 & 411 \\
\hline \multicolumn{9}{|l|}{ Syringe-borne virus prevalence } \\
\hline \multicolumn{9}{|l|}{ HIV serology } \\
\hline HIV positive & $159(57 \%)$ & $30(9 \%)$ & $46(15 \%)$ & $193(64 \%)$ & $42(13 \%)$ & $8(3 \%)$ & $44(15 \%)$ & $244(59 \%)$ \\
\hline Missing & $1(0 \%)$ & $1(<1 \%)$ & $6(2 \%)$ & 0 & $6(2 \%)$ & 0 & 0 & $11(3 \%)$ \\
\hline \multicolumn{9}{|l|}{ HCV serology } \\
\hline HCV positive & $236(85 \%)$ & $252(72 \%)$ & $152(51 \%)$ & $270(90 \%)$ & $164(49 \%)$ & $222(72 \%)$ & $183(61 \%)$ & $358(90 \%)$ \\
\hline Missing & $1(0 \%)$ & $1(<1 \%)$ & $6(2 \%)$ & 0 & $6(2 \%)$ & 0 & 0 & $11(3 \%)$ \\
\hline \multicolumn{9}{|l|}{ Individual level sociodemographic variables } \\
\hline \multicolumn{9}{|l|}{ Sex } \\
\hline Male & $193(69 \%)$ & $262(75 \%)$ & $272(89 \%)$ & $189(63 \%)$ & 259 (76\%) & $222(72 \%)$ & $210(70 \%)$ & $3000(73 \%)$ \\
\hline Missing & 0 & 0 & 0 & 0 & 0 & 0 & 0 & 0 \\
\hline \multicolumn{9}{|l|}{ Age } \\
\hline Mean & 26.7 & 29.7 & 24.7 & 28.1 & 28.0 & 31.0 & 26.0 & 29.9 \\
\hline Median & 26 & 29 & 24 & 28 & 28 & 30 & 26 & 29 \\
\hline Range & $16-43$ & $16-53$ & $15-51$ & 19-44 & $17-49$ & $16-63$ & $17-51$ & $15-57$ \\
\hline \multicolumn{9}{|l|}{ Individual level sociodemographic variables } \\
\hline \multicolumn{9}{|l|}{ Educational level } \\
\hline Not complete secondary & $10(4 \%)$ & $42(12 \%)$ & $6(2 \%)$ & $21(7 \%)$ & $1(0 \%)$ & 0 & 0 & $33(8 \%)$ \\
\hline Complete secondary & $230(82 \%)$ & $283(81 \%)$ & $260(85 \%)$ & $249(83 \%)$ & $266(78 \%)$ & $264(85 \%)$ & $216(72 \%)$ & $341(83 \%)$ \\
\hline Beyond secondary & $38(14 \%)$ & $25(7 \%)$ & $34(11 \%)$ & $30(10 \%)$ & $72(21 \%)$ & $45(15 \%)$ & $81(27 \%)$ & $29(7 \%)$ \\
\hline Missing data & $1(<1 \%)$ & 0 & $6(2 \%)$ & 0 & $2(1 \%)$ & 0 & $3(1 \%)$ & $8(2 \%)$ \\
\hline \multicolumn{9}{|l|}{ Individual level risk variables_-past month } \\
\hline \multicolumn{9}{|l|}{ Duration of injection (years) } \\
\hline Mean & 9.1 & 9.1 & 5.3 & 8.5 & 7.3 & 10.2 & 5.9 & 9.3 \\
\hline Median & 8 & 10 & 5 & 9 & 8 & 10 & 5 & 10 \\
\hline Range & $0-22$ & $0-32$ & $0-20$ & $0-16$ & $0-16$ & $0-40$ & $0-30$ & $0-34$ \\
\hline \multicolumn{9}{|l|}{ Injected with an HIV+ IDUs } \\
\hline Yes & $121(43 \%)$ & $14(4 \%)$ & $74(24 \%)$ & $138(46 \%)$ & $122(36 \%)$ & $7(2 \%)$ & $114(38 \%)$ & $216(53 \%)$ \\
\hline No & $78(28 \%)$ & $336(96 \%)$ & $164(54 \%)$ & $63(21 \%)$ & $155(45 \%)$ & $231(75 \%)$ & $184(61 \%)$ & $55(13 \%)$ \\
\hline Do not know & 0 & 0 & 0 & $96(32 \%)$ & 0 & 0 & 0 & $124(30 \%)$ \\
\hline Missing & $80(29 \%)$ & 0 & $68(22 \%)$ & $3(1 \%)$ & $64(19 \%)$ & $71(23 \%)$ & $2(1 \%)$ & $15(4 \%)$ \\
\hline \multirow{2}{*}{\multicolumn{9}{|c|}{$\begin{array}{l}\text { Individual level risk variables_-past month } \\
\text { Iniected with used syringe }\end{array}$}} \\
\hline Injected with used syringe & & & & & & & & \\
\hline More than half & $6(2 \%)$ & $12(3 \%)$ & $4(1 \%)$ & $6(2 \%)$ & $7(2 \%)$ & $3(1 \%)$ & $1(0 \%)$ & $38(7 \%)$ \\
\hline Half or fewer & $58(21 \%)$ & $104(30 \%)$ & $87(28 \%)$ & $34(11 \%)$ & $72(21 \%)$ & $93(30 \%)$ & $30(10 \%)$ & $141(34 \%)$ \\
\hline Never & 206 (74\%) & $233(67 \%)$ & $193(63 \%)$ & $259(86 \%)$ & $262(77 \%)$ & 206 (67\%) & $268(70 \%)$ & $223(54 \%)$ \\
\hline Missing data & $9(3 \%)$ & $1(<1 \%)$ & $22(7 \%)$ & $1(<1 \%)$ & 0 & $7(2 \%)$ & $1(<1 \%)$ & $9(2 \%)$ \\
\hline Shared paraphernalia & $73(26 \%)$ & $214(61 \%)$ & $184(60 \%)$ & $195(65 \%)$ & $273(80 \%)$ & $281(91 \%)$ & 227 (76\%) & $316(77 \%)$ \\
\hline Shared rinse water & 89 (32\%) & $154(44 \%)$ & $116(38 \%)$ & $114(38 \%)$ & $106(31 \%)$ & $111(36 \%)$ & $36(12 \%)$ & $255(62 \%)$ \\
\hline Injected with prefilled syringes & $75(27 \%)$ & $154(44 \%)$ & $83(27 \%)$ & $84(28 \%)$ & $85(25 \%)$ & $179(58 \%)$ & $111(37 \%)$ & $86(21 \%)$ \\
\hline Injected methamphetamine-like stimulants & 0 & $14(4 \%)$ & $30(10 \%)$ & $89(30 \%)$ & 62 (18\%) & $7(2 \%)$ & $79(26 \%)$ & $30(7 \%)$ \\
\hline
\end{tabular}


Table 2 Association of individual-level demographic, risk and protective factors with HIV prevalence in eight Russian cities

\begin{tabular}{|c|c|c|}
\hline Variable & Crude OR ( $\pm 95 \% \mathrm{Cl})$ & Adjusted OR $( \pm 95 \% \mathrm{Cl})$ \\
\hline Sex & $1.09(0.90$ to 1.31$)$ & \\
\hline Age & 1.01 (0.99 to 1.02$)$ & \\
\hline Educational level & $0.78(0.53$ to 1.17$)$ & \\
\hline Duration of injection & $1.02(1.01$ to 1.04$)$ & 1.01 (0.99 to 1.03$)$ \\
\hline Injected with used syringe, last 30 days & $1.46(1.21$ to 1.76$)$ & $0.86(0.66$ to 1.12$)$ \\
\hline Injected with known HIV+, last 30 days & 1.96 (1.74 to 2.21$)$ & $1.86(1.64 \text { to } 2.11)^{\star * *}$ \\
\hline Shared paraphernalia, last 30 days & 1.58 (1.33 to 1.88$)$ & $1.11(0.89$ to 1.38$)$ \\
\hline Shared rinse water, last 30 days & 2.30 (1.93 to 2.74$)$ & $2.29(1.78 \text { to } 2.96)^{* \star *}$ \\
\hline Injected with prefilled syringes, last 30 days & $1.06(0.88$ to 1.28$)$ & \\
\hline Injected methamphetamine-like drugs, last 30 days & $1.10(0.88$ to 1.39$)$ & \\
\hline Always injected with sterile syringe, last 30 days & 0.99 (0.82 to 1.19$)$ & \\
\hline Used harm reduction services, last 12 months & $0.77(0.61$ to 0.98$)$ & $0.74(0.56 \text { to } 0.97)^{*}$ \\
\hline Ever in treatment for addiction & $0.92(0.76$ to 1.10$)$ & \\
\hline Perfect score on HIV knowledge test & $0.73(0.62$ to 0.87$)$ & $0.78(0.65 \text { to } 0.95)^{*}$ \\
\hline
\end{tabular}

associated, whereas the recent use of a syringe exchange programme and perfect score on the HIV knowledge test was protective. None of the sexual risk behaviours considered in the survey instrument (unprotected sexual intercourse, number of recent or HIV-positive partners and engagement in commercial sex) was significantly associated with HIV prevalence.

In the second model, we determined which of the three network-level variables (RDS network size, mean chain length and frequency of meeting the recruiter) were correlated with HIV prevalence and added these to the four individual-level variables (table 3). Although both larger self-reported network size and shorter length of an individual's referral chain were significantly associated with prevalence in bivariate analysis, the multivariate model excluded the length of the referral chain and did not eliminate any of the four significant individual-level variables.

In the third model, we determined which of the three city-level variables were correlated with HIV prevalence and added these to the five previously identified variables (table 4). All were found to be significantly associated with HIV prevalence in bivariate analysis, but only two were in the multivariate analysis. The predominance of commercial heroin was positively associated with prevalence, whereas larger mean recruitment chain length was protective. One of the individual-level variables, recent use of syringe exchange, was no longer protective in this model. Of the six factors associated with HIV prevalence, the variable with the strongest predictive value was the city-level variable commercial heroin predominance. We explored the possibility of autocorrelation among these variables as well as variables significantly associated with HIV prevalence in all previous models (table 5). We found that of the eight variables, only two-sharing cookers and higher levels of MTS injecting-were not correlated and all the variables that remained significant in the third model were collinear with commercial heroin predominance.

Given the high degree of collinearity, we constructed one final model using hierarchical modelling controlling for commercial heroin predominance as a random effect (table 6). The results of this model are consistent with the third model presented in table 4 despite the high collinearity of the significant variable. It is interesting to note that in the hierarchical model, the intercept is not statistically significant, suggesting that incorporating the variable of commercial heroin predominance as a random variable accounts for much of the variation in the data.

\section{DISCUSSION}

This study, using bio-behavioural surveillance data on HIV prevalence among people who inject drugs from eight

Table 3 Association of individual-level and network-level factors with HIV prevalence in eight Russian cities

\begin{tabular}{|c|c|c|}
\hline Variable & Crude OR (95\% Cl) & Adjusted OR $(95 \% \mathrm{Cl})$ \\
\hline RDS network size, last 6 months & $1.003(1.001$ to 1.004$)$ & $1.003(1.001 \text { to } 1.005)^{\star \star}$ \\
\hline Length of referral chain & 0.998 (0.996 to 0.999$)$ & 0.999 (0.997 to 1.0006$)$ \\
\hline Frequency of meeting referrer & $1.09(0.91$ to 1.32$)$ & \\
\hline Injected with known HIV+, last 30 days & - & $1.86(1.64 \text { to } 2.1)^{\star \star \star}$ \\
\hline Shared rinse water, last 30 days & - & $2.26(1.86 \text { to } 2.74)^{\star \star *}$ \\
\hline Used harm reduction services, last 12 months & - & $0.75(0.57 \text { to } 0.98)^{\star}$ \\
\hline Perfect score on HIV knowledge test & - & $0.76(0.63 \text { to } 0.92)^{* *}$ \\
\hline
\end{tabular}


Table 4 Association of individual-level, network-level and city-level factors with HIV prevalence in eight Russian cities

\begin{tabular}{|c|c|c|}
\hline Variable & Crude OR (95\% CI) & Adjusted OR (95\% Cl) \\
\hline Mean city recruitment chain length & 0.99 (0.98 to 0.99$)$ & $0.992(0.989 \text { to } 0.995)^{\star \star \star}$ \\
\hline Commercial heroin predominant in city & $6.11(4.53$ to 8.24$)$ & $3.28(2.36 \text { to } 4.56)^{\star \star \star}$ \\
\hline Amphetamine-type drugs more common & 1.29 (1.09 to 1.54$)$ & $1.17(0.94$ to 1.45$)$ \\
\hline RDS network size, last 6 months & - & $1.0025(1.001 \text { to } 1.004)^{\star *}$ \\
\hline Injected with known HIV+, last 30 days & - & $1.58(1.39 \text { to } 1.80)^{\star \star \star}$ \\
\hline Shared rinse water, last 30 days & - & $1.94(1.58 \text { to } 2.37)^{\star \star \star}$ \\
\hline Used harm reduction services, last 12 months & - & $0.87(0.66$ to 1.16$)$ \\
\hline Perfect score on HIV knowledge test & - & $0.79(0.65 \text { to } 0.96)^{*}$ \\
\hline
\end{tabular}

widely separated and divergent Russian cities, provides the clearest picture to date of the Russian HIV epidemic in this at-risk group. The thrust of the analysis, which is exploratory in nature, seeks to identify the characteristics at the individual, network and city level that might provide some explanation for the differences in HIV prevalence across the eight cities in the Russian Federation. Three distinct features of the epidemic emerge from the analysis. First, among the best explanations for the substantial heterogeneity in HIV prevalence, is a strong association between the nature of the drug market and HIV prevalence. Second, is the finding that there appears to be about a $20 \%$ reduction in the likelihood of HIV infection among those individuals with greater HIV knowledge and a 25\% reduction among those who availed themselves of syringe exchange programme (although the latter association disappeared when drug markets were considered). Third, on the individual-level shared paraphernalia other than syringes (in our case-shared rinse water) is an important factor of HIV transmission. Each of these will be considered in the paragraphs below. High prevalence was not restricted to any one region of Russia, but was seen in cities ranging from Irkutsk in central Siberia (and the eastern and southernmost city in the study) to St Petersburg (the western and northernmost city in the study). There was also no apparent association between population size and HIV prevalence (Spearman $r_{s}=0.407$, $\mathrm{p}>0.05$ ), suggesting that the epidemic was not simply concentrated in larger cities. Instead, HIV prevalence is higher in cities in which the form of heroin has made the transition from homemade to commercial. The explanation for this association is unclear, but several nonexclusive possibilities exist.

First, it is possible that the relative ease of using commercial heroin-no need to spend time manufacturing the heroin or to inject large volumes of weak drug solutions-has led to increases in the number of IDUs and hence to changes in the social networks whose interrelationship and whose injection behaviours may foster the spread of blood-borne viruses. The correlation of smaller network sizes across different measures of the network size may be a consequence of market changes in which fewer connections are needed to obtain commercial heroin compared with that needed to secure a reliable supply of homemade opiates. That many of the injection risk and network variables are collinear in cities where commercial heroin is dominant (as shown in table 5) is supportive of but by no means proof of such a hypothesis. Factors such as the structure, density and stability of those networks could be the key ones that lead to differences in HIV-related risks in among IDU networks. ${ }^{34} 35$ A second possible explanation lies in the differences in practices regarding the use of commercial and homemade heroin that include how these drugs are distributed, prepared and injected. Such phenomena have been described in other studies suggesting that the formulation of heroin can play a significant role in drug preparation and administration practices linked

Table 5 Collinearity of city-level commercial heroin predominance and other variables

\begin{tabular}{llcc}
\hline Variable name & Variable level & Z statistic & p Value \\
\hline Injected with known HIV+, last 30 days & Individual & 10.16 & $<.00001$ \\
Shared sinse water, last 30 days & Individual & 8.192 & $<0.00001$ \\
Shared cooker & Individual & -1.713 & 0.0867 \\
Used harm reduction Services, last 12 months & Individual & -3.354 & $<.00001$ \\
Perfect score on HIV Knowledge test & Individual & 2.461 & 0.0138 \\
Individuals' RDS network size & Network & 1.993 & 0.0463 \\
Mean city recruitment Chain length & City & -16.62 & 1.233 \\
Amphetamine-type drugs more common & City & & 0.00001 \\
RDS, respondent-driven sampling. & &
\end{tabular}


Table 6 Hierarchical Generalised Logistic Model of HIV prevalence in eight Russian cities

\begin{tabular}{llccc}
\hline Variable & Estimate & t value & p Value & Adjusted OR (95\% Cl) \\
\hline Mean city Recruitment chain length & 0.0088 & -4.729 & $<0.0001$ & $0.99(0.987$ to 0.994$)$ \\
Amphetamine-type drugs more common & 0.084 & 0.685 & 0.49 & - \\
RDS network size, last 6 month & 0.0025 & -2.898 & 0.0038 & $1.003(1.001$ to 1.004$)$ \\
Injected with known HIV+, last 30 days & 0.483 & 7.197 & $<0.0001$ & $1.61(1.41$ to 1.84$)$ \\
Shared rinse water, last 30 days & 0.679 & 6.368 & $<0.0001$ & $1.96(1.58$ to 2.42) \\
Used harm Reduction services, last 12 months & 0.140 & 0.937 & 0.35 & - \\
Perfect score on HIV knowledge test & 0.235 & -2.231 & 0.026 & $0.79(0.64$ to 0.97) \\
Intercept & 1.204 & -1.933 & 0.053 & - \\
\hline
\end{tabular}

to the spread of HIV. ${ }^{36-40}$ Laboratory data simulating Russian drug preparation practices demonstrated that HIV is more easily transmitted when using commercial heroin. The replication of homemade heroin production, based upon ethnographic observations of the process, revealed that not only did HIV fail to survive the manufacturing process but also that something extracted during the process reduced the viability of HIV by $80 \%$ when the homemade drug was stored inside syringes contaminated with HIV-infected blood. ${ }^{36}$

There also appear to be modest protective effects from increased HIV knowledge and attendance at harm reduction programmes. The one-fifth reduction in the odds of being HIV positive among those who achieved the highest score on the HIV knowledge test suggests an important role for expanding HIV educational activities targeting IDUs. As detailed in many theories of HIV prevention, knowledge is necessary, but not necessarily sufficient to reduce risk behaviours and disease transmission. ${ }^{41-43}$ Knowledge must be complemented by motivation to reduce risk and access to prevention tools. On the other hand, according to the data presented herein and from other studies, harm reduction programmes in Russia have usually attained insufficient coverage to be effective in lowering HIV transmission. ${ }^{44} 45$ This may explain why the degree of protective effect is small and becomes non-significant once city-level variables are considered: although the use of a local SEP may be protective in cities where they exist, their existence itself is a citylevel effect. There was no evidence of protective effect from having been in drug abuse treatment, either ever or within the past year. This could be considered as an effect of Russian narcology policy, which is focused on achieving abstinence but not on harm reduction for those who do not achieve sustained remission. ${ }^{46}$

Our study shows that sharing non-syringe injection paraphernalia is common among Russian IDUs and it significantly correlates which positive HIV status. This means that, along with the need to expand the access to clean syringes that is still insufficient due low NSP coverage and IDUs' negative experience of purchasing syringes from the pharmacies, ${ }^{18}{ }^{47-50}$ efforts to reduce sharing of paraphernalia, including rinsing water, are urgently needed.

There are several limitations to this study. Two have to do with sampling. First, the selection of the eight cities was arbitrary-no selection method was developed to ensure that the eight cities were representative of the range of characteristics of IDUs, drug markets or prevention activities found in the Russian Federation. Thus, there is no way to generalise these finding to other Russian cities. Second, although the same recruitment method was used to accrue samples in each city, the recruitment pattern was city-specific. This is reflected in the differences in average chain length, which ranged from 33 in Irkutsk to 112 in Chelyabinsk. There is no sampling frame for random selection within the hidden population of IDUs and no evidence that the samples of IDUs are representative of the underlying population from which the sample was drawn; therefore, they must be considered convenience samples. A major limitation is that its cross-sectional nature makes the study exploratory rather than being definitely able to establish causality. The outcome measure of interest, HIV prevalence, may have occurred at any time in the past, whereas the assessment of individual level risk and protective behaviours, network attributes and heroin market features were ascertained for the recent past only. There is a limitation resulting from the data we considered in our models. As our modelling was hypothesis-driven, variables concerning risky sexual behaviours were not included in the models because they failed to predict HIV prevalence in any of the eight cities. A final limitation is the absence of data on mortality, incarceration and migration of IDU populations. Nevertheless, compared with the past research, this was conducted in a way that covered the largest range of Russian cities yet studied.

In summary, despite the above limitations, this report, which is based on the application of common recruitment, screening, survey and testing methods, provides the best snapshot of the current HIV epidemic among IDUs in Russia. The findings reveal that HIV prevalence is very high among members of this risk group in several cities and that the factor that goes farthest in explaining high prevalence is the predominance of a commercial heroin market. If a market transition is a pre-requisite for increasing prevalence, then subsequent surveillance should be conducted in the cities that have experienced the transition, but still have low prevalence and in the cities that have yet to make this transition. Furthermore, more active prevention programmes are urgently 
needed, including such measures as the increase of HIV-related knowledge, expanded syringe and sterile equipment access, appropriate addiction treatment, increases in antiretroviral therapy specifically for IDUs who remain the risk group with highest incidence and prevalence and promotion of safer sex and sexual risk reduction among IDUs who are at risk of spreading HIV to their non-drug-using sex partners.

\section{Author affiliations}

${ }^{1}$ NGO Stellit, St Petersburg, Russian Federation

2Department of Psychology, Saint-Petersburg State University, St Petersburg, Russian Federation

${ }^{3}$ Center for Interdisciplinary Research on AIDS, Yale University, School of

Public Health, New Haven, Connecticut, USA

${ }^{4}$ Northwest Regional AIDS Center, St Petersburg, Russian Federation

Acknowledgements Authors would like to thank regional organisations which participated in data collection: Voronezh AIDS Center, Voronezh NGO Anti-AIDS Center, Irkutsk AIDS Center, Irkutsk NGO 'ANTI-AIDS Priangar'e', Irkutsk Red Cross, Chelyabinsk AIDS Center, Chelyabinsk Center Compass, N. Chelny AIDS Center, Timur Islamov Foundation, Yekaterinburg NGO 'Novie grani', Orel NGO 'Phoenix Plus', Siberian Interregional organization 'AntiAIDS-Siberia' and Omsk AIDS Center. Authors would also like to thank Dr Natalia Ladnaia for the valuable comments for the first draft of the article.

Contributors KE, OSL, RH, VO, MMR and TTS designed the study. KE, TTS and OSL were responsible for data collection, $\mathrm{RH}$ led the analysis with input from RB, RH with input from RB and KE wrote the first draft of the manuscript and all authors contributed to and approved the final version.

Funding The overall work on Voronezh, N.Chelny, Irkutsk and Chelyabinsk for data collection and analysis was implemented within the framework of WHO Russia HIV/AIDS programme activities and as a part of the UNODC project 'Scaling-up, and improving access to, HIV/AIDS prevention and care programmes for injecting drug users and in prison settings of Russian Federation (TD/RUS/J17)' and performed by NGO Stellit in collaboration with Federal AIDS centre and regional partners. Research in Omsk, Yekaterinburg and Orel was performed by NGO Stellit and regional study partners with financial and technical support by Russian Harm Reduction Network (ESVERO). Research in St Petersburg was carried out by NGO Stellit and North-West AIDS Center with financial support by Government of Finland and technical support of UNODC office in Russian Federation. Secondary data analysis was supported by grants from the Civilian Research and Development Foundation (RUB7001-ST-08), the U.S. National Institute of Mental Health (5P30MH062294), and the Fogarty International Center at NIH (5D43TW001028).http://www.icmje.org/ coi_disclosure.pdf

\section{Competing interests None.}

Ethics approval Obtained from Saint-Petersburg State University (Russia) and Federal State Institution of Science 'Central Research Institute of Epidemiology' by Rospotrebnadzor (Russia)

Provenance and peer review Not commissioned; externally peer reviewed.

Data sharing statement No additional data are available.

\section{REFERENCES}

1. UNAIDS. The changing HIV/AIDS epidemic in Europe and Central Asia. Geneva, Switzerland: UNAIDS, 2004.

2. UNAIDS. UNAIDS Report on the Global AIDS Epidemic. Geneva, Switzerland: UNAIDS, 2010

3. Federal AIDS Center. Number of registered HIV-positive among Russian citizens on 31.12.2011, 2012.

4. Goliusov AT, Dementyeva LA, Ladnaya NN, et al. Country Progress Report of the Russian Federation on the Implementation of the Declaration of Commitment on HIV/AIDS. Moscow: Federal Service for Surveillance of Consumer Rights Protection and Human Well-Being of the Russian Federation, 2008.
5. National Research Narcology Center. Main indicators of narcology services in the Russian Federation in 2008-2009. Moscow, RF: National Research Narcology Center, 2010.

6. Human Rights Watch. Rehabilitation required: Russia's human rights obligation to provide evidence-based drug dependence treatment. New York, USA: Human Rights Watch, 2007.

7. UN Office on Drugs and Crime. World drug report, 2009. Vienna, Austria: UNODC, 2009.

8. Wingfield-Hayes R. The heroin epidemic advancing on Russia. BBC Radio 2010

9. Niccolai LM, Toussova OV, Verevochkin SV, et al. High HIV prevalence, suboptimal HIV testing, and low knowledge of HIV-positive serostatus among injection drug users in St. Petersburg, Russia. AIDS Behav 2010;14:932-41.

10. Rhodes T, Lowndes C, Judd A, et al. Explosive spread and high prevalence of HIV infection among injecting drug users in Togliatti City, Russia. AIDS 2002;16:F25-31.

11. Rhodes T, Platt L, Maximova S, et al. Prevalence of HIV, hepatitis C and syphilis among injecting drug users in Russia: a multi-city study. Addiction 2006;101:252-66.

12. Chen $\mathrm{CY}$, Lin KM. Health consequences of illegal drug use. Curr Opin Psychiatry 2009;22:287-92.

13. Lelutiu-Weinberger C, Pouget ER, Des Jarlais DD, et al. A meta-analysis of the hepatitis $\mathrm{C}$ virus distribution in diverse racial/ ethnic drug injector groups. Soc Sci Med 2009;68:579-90.

14. Thomson BJ. Hepatitis $\mathrm{C}$ virus: the growing challenge. Br Med Bull 2009;89:153-67.

15. Paintsil E, Verevochkin SV, Dukhovlinova E, et al. Hepatitis C virus infection among drug injectors in St. Petersburg, Russia: social and molecular epidemiology of an endemic infection. Addiction 2009:104:1881-90.

16. Aceijas $\mathrm{C}$, Rhodes T. Global estimates of prevalence of HCV infection among injecting drug users. Int J Drug Policy 2007;18:352-8.

17. Dehne KL, Khodakevich L, Hamers FF, et al. The HIV/AIDS epidemic in eastern Europe: recent patterns and trends and their implication for policy making. AIDS 1999;13:741-9.

18. Heimer R, Booth RE, Irwin KS, et al. In: Twigg JL, ed. HIV/AIDS in Russia and Eurasia. Basingstoke, Hampshire, UK: Palgrave Macmillan, 2007.

19. Rhodes T, Sarang A, Bobrik A, et al. HIV transmission and HIV prevention associated with injecting drug use in the Russian Federation. Int J Drug Policy 2004;15:1-16.

20. Sergeyev B, Oparina T, Rumyantseva TP, et al. HIV Prevention for drug injectors in Yaroslavl, Russia: a peer-driven intervention and needle exchange. J Drug Issues 1999;29:777-804.

21. Heimer R, Kinzly ML, $\mathrm{He} \mathrm{H}$, et al. The effect of acids on the survival of HIV during drug injection. J AIDS 2007:144-50.

22. UN Office on Drugs and Crime. World Drug Report, 2004. Vienna, Austria: UNODC, 2004.

23. Paoli L. The development of an illegal market. Drug consumption and trade in post-Soviet Russia. Br J Criminol 2002;42:21-39.

24. Niccolai LM, Shcherbakova IS, Toussova OV, et al. The potential for bridging of HIV transmission in Russian Federation: sex risk behaviors and HIV prevalence among drug users (DUs) and their non-DU sex partners. J Urban Health 2009;86(Suppl 1):131-43.

25. Platt L, Rhodes T, Hickman M, et al. Changes in HIV prevalence and risk among new injecting drug users in a Russian city of high HIV prevalence. J AIDS 2008;47:623-31.

26. Shaboltas AV, Toussova OV, Hoffman IF, et al. HIV prevalence, socio-demographic and behavioral correlates and recruitment methods among injection drug users in St. Petersburg, Russia. J Acquir Immune Defic Syndr 2006;41:657-63.

27. Heckathorn DD. Respondent-driven sampling; a new approach to the study of hidden populations. Soc Probl 1997;44:174-99.

28. Heckathorn DD, Semaan S, Broadhead RS, et al. Extensions of respondent-driven sampling: a new approach to the study of injection drug users aged 18-25. AIDS Behav 2002;6:55-67.

29. Heckathorn D. Respondent driven sampling II: deriving valid population estimates from chain-referral samples of hidden populations. Soc Probl 2002;49:11-34.

30. Salganik MJ, Heckathorn DD. Sampling and estimation in hidden populations using respondent-driven sampling. Sociol Methodol 2004;34:193-240.

31. Volz E, Heckathorn DD. Probability based estimation theory for respondent-driven sampling. J Official Stat 2008;24:79-97.

32. Family Health International. Behavioral surveillance surveys: guidelines for repeated behavioral surveys in populations at risk of HIV. Arlington, VA, 2000

33. Ronnegard L, Shen X, Alam M. hglm: a package for fitting hierarchical generalized linear models. $R$ J 2010;2:20-8. 
34. De P, Cox J, Boivin J, et al. The importance of social networks in their association to drug equipment sharing among injection drug users: a review. Addiction 2007;102:1730-9.

35. Neaigus A, Friedman SR, Curtis R, et al. The relevance of drug injectors' social and risk networks for understanding and preventing HIV infection. Soc Sci Med 1994;38:67-78.

36. Abdala N, Grund J-PC, Tolstov Y, et al. Can homemade injectable opiates contribute to the HIV epidemic among injection drug users in the countries of the former Soviet Union? Addiction 2006;101:731-7.

37. Ciccarone D. Heroin in brown, black and white: structural factors and medical consequences in the US heroin market. Int J Drug Policy 2009;20:277-82.

38. Ciccarone D, Bourgois P. Explaining the geographical variation of HIV among injection drug users in the United States. Subst Use Misuse 2003;38:2049-63.

39. Clatts MC, Heimer R, Abdala N, et al. Illicit drug injection and HIV-1 transmission: heating drug solutions may inactive HIV-1. J Aquir Immune Defic Syndr 1999;22:194-9.

40. de la Fuente L, Saavedra P, Barrio G, et al. Temporal and geographic variations in the characteristics of heroin seized in Spain and their relation with the route of administration. Drug Alcohol Depend 1996;40:185-94.

41. Avants SK, Warburton LA, Hawkins KA, et al. Continuation of high-risk behavior by HIV-positive drug users. Treatment implications. J Subst Abuse Treat 2000;19:15-22.
42. Fisher JD, Fisher WA. Changing AIDS risk behavior. Psychol Bull 1992;111:455-74.

43. Prochaska JO, Redding CA, Harlow LL, et al. The transtheoretical model of change and HIV prevention: a review. Health Educ $Q$ 1992;21:471-86.

44. Burrows D, Sarang A. Mixed signals: responses to HIV/AIDS in the Russian Federation. Washington, DC: The World Bank, 2004.

45. Sarang A, Stuikyte R, Bykov R. Implementation of harm reduction in Central and Eastern Europe and Central Asia. Int J Drug Policy 2007;18:129-35.

46. Torban MN, Heimer R, llyuk RD, et al. Practices and attitudes of addiction treatment providers in the Russian Federation. J Addict Res Ther 2011;2.

47. Csete J. Lessons not learned: human rights abuses and HIV/AIDS in the Russian Federation. Hum Rights Watch 2004;16:1-62.

48. Fedorova EV, Skochilov RV, Heimer R, et al. Access to syringes for HIV prevention for injection drug user in St. Petersburg, Russia: syringe purchase test study. BMC Public Health 2013;epub ahead of print:13:183

49. Sarang A, Rhodes T, Sheon N, et al. Policing drug users in Russia: risk, fear, and structural violence. Subst Use Misuse 2010; 45:813-64.

50. Sarang A, T R, Platt L. Access to syringes in three Russian cities: implications for syringe distribution and coverage. Int J Drug Policy 2008;19(Suppl 1):25-36. 